\title{
Subarachnoid Hematoma Attenuates Vasodilation and Potentiates Vasoconstriction Induced by Vasoactive Agents in Newborn Pigs
}

\author{
M. A. YAKUBU, M. SHIBATA, ${ }^{1}$ AND C. W. LEFFLER \\ Laboratory for Research in Neonatal Physiology, Brain Injury Research Center, Department of \\ Physiology and Biophysics, University of Tennessee, Memphis, Tennessee 38163
}

\begin{abstract}
\begin{tabular}{|c|c|}
\hline \multicolumn{2}{|c|}{ ABSTRACT } \\
\hline $\begin{array}{l}\text { The effects of perivascular blood on pial arteriolar vasore- } \\
\text { activity to selected vasodilators and vasoconstrictors were } \\
\text { examined in vivo in a newborn pig model. } \alpha \text {-Chloralose- } \\
\text { anesthetized newborn pigs were fitted with closed cranial } \\
\text { windows } 4 \mathrm{~d} \text { after cortical subarachnoid injections of autol- } \\
\text { ogous blood. The responsiveness of pial arterioles to topical } \\
\text { application of dilator agents [iloprost, prostaglandin } \mathrm{E}_{2} \\
\text { (PGE } \mathrm{E}_{2} \text {, histamine, and sodium nitroprusside (SNP)] and } \\
\text { vasoconstrictor agents [leukotriene } \mathrm{C}_{4} \text { and endothelin-1 } \\
\text { (ET-1) in artificial cerebrospinal fluid was studied in control } \\
\text { and blood-injected piglets. Pial arterioles dilated dose depen- } \\
\text { dently in response to topical application of iloprost, PGE } \\
\text { histamine, and SNP in the control group, with increases in } \\
\text { diameter of } 54,44,67 \text {, and } 50 \% \text { at } 10^{-8} \mathrm{M}, 10^{-5} \mathrm{M}, 10^{-5} \mathrm{M} \text {, } \\
\text { and } 10^{-5} \mathrm{M} \text {, respectively. These dilations in response to } \\
\text { iloprost, PGE } \text {, and histamine in the blood-injected piglets } \\
\text { were significantly attenuated to } 23,18 \text {, and } 34 \% \text {, respec- } \\
\text { tively, whereas the dilation in response to SNP was not } \\
\text { changed }(64 \%) \text {. Constrictions in response to } 10^{-8} \mathrm{M} \text { leuko- } \\
\text { triene } \mathrm{C}_{4} \text { and ET- } 1 \text { were } 16 \text { and } 26 \% \text { and were potentiated by }\end{array}$ & $\begin{array}{l}\text { hematoma to } 36 \text { and } 43 \% \text {, respectively. The lowest dose of } \\
\text { ET-1 }\left(10^{-12} \mathrm{M}\right) \text { significantly dilated pial arterioles in the } \\
\text { control but not in the blood-treated group. We conclude that } \\
\text { prolonged exposure of pial arterioles to perivascular blood } \\
\text { attenuates cerebrovascular dilation in response to selected } \\
\text { vasoactive agents (iloprost, } \mathrm{PGE}_{2} \text {, and histamine) but not to } \\
\text { SNP, suggesting that blood-induced attenuation of vasodila- } \\
\text { tion and the generalized vasoconstriction may involve inhib- } \\
\text { iting the prostanoid/cAMP signaling pathway. Potentiation } \\
\text { of vasoconstriction induced by ET-1 and leukotriene } \mathrm{C}_{4} \text { in } \\
\text { the hematoma group could be due to loss of this dilator } \\
\text { influence. (Pediatr Res } \mathbf{3 6 : 5 8 9 - 5 9 4 , ~ 1 9 9 4 ) ~} \\
\text { aCSF, artificial cerebrospinal fluid } \\
\text { ET-1, endothelin-1 } \\
\text { LTC } \\
\text { PGF leukotriene } \mathrm{C}_{4} \\
\text { PGE }_{2} \text {, prostaglandin } \mathrm{F}_{2 \alpha} \\
\text { SNP, sodium nitroprusside }\end{array}$ \\
\hline
\end{tabular}
\end{abstract}
Intraventricular and periventricular cerebral hemorrhages occur frequently in preterm babies, whereas subarachnoid hemorrhages occur in both term and preterm infants (1-3). In adults and children, subarachnoid hemorrhage can also result from trauma, asphyxia, brain injury, or rupture of an intracranial aneurysm (4-6). In adults, one of the major complications of cerebral hemorrhage is a delayed cerebral ischemia due to abnormal vasoconstriction of large cerebral arteries that usually presents itself 4-7 d after the hemorrhage. Alterations of cerebral circulation and metabolism can develop secondary to cerebral vasoconstriction, resulting in death or permanent cerebral dysfunction (4-8). Despite much re-

Received November 15, 1993; accepted June 5, 1994.

Correspondence: Dr. Charles W. Leffler, The University of Tennessee, Department of Physiology and Biophysics, 894 Union Ave., Memphis, TN 38163.

Supported by grants from the National Institutes of Health.

${ }^{1}$ Present address: Yamanashi Medical College, Tamaho, Nakakoma, Yamanashi 409-38, Japan. search into the etiology of hemorrhage-induced vasoconstriction (4-8), our understanding of the mechanism by which cerebral arterial vasoconstriction occurs after cerebral hemorrhages is still limited. Much less information is available on the effects of hematoma on cerebral circulation in neonates.

Vasodilator products of prostaglandin $\mathrm{H}$ synthase are prominent components in the regulation of cerebral hemodynamics in neonatal pigs, contributing to hypercapnia-, hypotension-, and histamine-induced cerebral vasodilation (9). In contrast, $\mathrm{PGF}_{2 \alpha}$, peptidoleukotrienes, and thromboxanes are potent cerebral vasoconstrictors (9). In addition, ET-1, a 21-amino acid peptide that was isolated from cultured porcine aortic endothelial cells (10), causes dilation of piglet pial arterioles at extremely low doses but powerful dose-dependent constriction at higher doses (11).

Cerebral dilations in response to hypercapnia and hypotension are markedly attenuated $4 \mathrm{~d}$ after intracranial 
blood injection in newborn pigs (12). Cerebrovascular constriction to norepinephrine is also reduced, but constriction to acetylcholine is not affected (13). In dog and monkey models of subarachnoid hematoma, reduced synthesis of dilator prostanoids has been observed $(8$, 14-17), but no change was observed in the piglet model (18). Increased secretion of spasmogenic agents such as $\mathrm{PGF}_{2 \alpha}, \mathrm{LTC}_{4}$, and ET-1 have been reported after hemorrhage $(8,18-20)$. Studies in adult humans showed elevated levels of vasoconstrictor agents: thromboxanes, leukotrienes, $\mathrm{PGF}_{2 \alpha}, \mathrm{ET}-1$, and oxyhemoglobin in the cerebrospinal fluid after subarachnoid hemorrhage (6-8, 21-25). Hence, eicosanoid and endothelin production systems could contribute to inappropriate cerebral vasoconstriction after subarachnoid hemorrhage.

However, despite changes reported in the levels of vasoactive agents in clinical and experimental subarachnoid hematoma, there is very little information in the literature on the effects of cerebral blood on vasoreactivity in response to these endogenous vasoactive agents in vivo in the newborn. The purpose of this study was to test the hypothesis that cerebral hematoma alters pial arteriolar vasoreactivity to prostanoids, leukotrienes, and ET-1 in vivo in newborn pigs.

\section{METHODS}

Animal protocols were reviewed and approved by the Animal Care and Use Committee of The University of Tennessee, Memphis, and animals were maintained in an American Association for Accreditation of Laboratory Animal Care accredited program. Piglets $1-3 \mathrm{~d}$ old $(1.0-2.5 \mathrm{~kg})$ were used for the experiments. The piglets received either sterile aCSF (control group) or $3 \mathrm{~mL}$ of autologous blood (cerebral hematoma group) injected onto the surface of the cerebral cortex and left for $4 \mathrm{~d}$ before we examined their responses to various vasoactive agents.

For placement of blood or aCSF, the piglets were anesthetized to effect (typically with $1 \%$ halothane initially, decreased to $0.4 \%$ halothane, $45 \%$ nitrous oxide, and $21 \%$ oxygen after $2 \mathrm{~min}$ ). Using aseptic procedures, a small hole was made in the skull over the left frontal cortex. Then a 22-gauge Teflon catheter (Angiocath, Deseret Co., Sandy, UT) was used to pierce the dura at an angle to the surface sufficient to prevent penetration into the brain. After removal of the needle, the tip of the catheter was advanced $2 \mathrm{~cm}$ posteriorly under the dura to the parietal cortex. Then $3 \mathrm{~mL}$ of either sterile aCSF or fresh, sterile, nonheparinized blood (removed via puncture of the precava) was injected over 1-2 min. The catheter was removed, the hole filled with sterile bone wax, and the scalp sutured. The piglets were treated with gentamicin and benzathine penicillin postoperatively. After surgery, piglets did not show any apparent behavioral abnormalities.

Four $\mathrm{d}$ after the injection, piglets were anesthetized with a mixture of ketamine hydrochloride $(33 \mathrm{mg} / \mathrm{kg}$ intramuscularly) and acepromazine $(3.3 \mathrm{mg} / \mathrm{kg}$ intramuscu- larly) and maintained with $\alpha$-chloralose $(50 \mathrm{mg} / \mathrm{kg}$ i.v., followed by $3-5 \mathrm{mg} / \mathrm{kg} / \mathrm{h}$ ). The femoral artery and vein were cannulated. The arterial catheter was used for the monitoring of blood pressure and blood sampling for gases and $\mathrm{pH}$ analysis, and the venous catheter was used for the administration of anesthesia or fluid. The trachea was cannulated, and the animals were ventilated mechanically with air. The body temperature was maintained at $37-38^{\circ} \mathrm{C}$ with a heating pad.

For the implantation of a closed cranial window, the scalp over the left parietal cortex was cut and retracted, and a hole $2 \mathrm{~cm}$ in diameter was made in the skull. The dura and arachnoid were removed, and a stainless steel and glass cranial window with needle ports was placed in the hole and secured with dental acrylic. The space under the window $(500 \mu \mathrm{L})$ was filled with aCSF composed of $(\mathrm{mM}) 3.0 \mathrm{KCl} ; 1.5 \mathrm{MgCl}_{2} ; 1.5 \mathrm{CaCl}_{2} ; 132 \mathrm{NaCl}$; 6.6 urea, 3.7 dextrose, and $24.6 \mathrm{NaHCO}_{3}$, with $7.39 \mathrm{pH}$, $6.1 \mathrm{kPa} \mathrm{PCO}_{2}$, and $5.7 \mathrm{kPa} \mathrm{Po}_{2}$. Pial arterioles were observed with a dissecting microscope, a television camera mounted on the microscope, and a video monitor. A video microscaler was used to measure vascular diameter.

After confirming that the blood pressure, the $\mathrm{pH}$, and the blood gases were within the normal range, control measurements of pial arteriolar diameter(s) were taken after the placement of aCSF containing no drug under the window. Vasoreactivity responses to topical application of iloprost, a stable analog of prostaglandin $\mathrm{I}_{2}\left(10^{-12}\right.$ $\left.10^{-8} \mathrm{M}\right), \mathrm{PGE}_{2}\left(10^{-9}-10^{-5} \mathrm{M}\right)$, histamine $\left(10^{-8}-10^{-5} \mathrm{M}\right)$, SNP $\left(10^{-8}-10^{-5} \mathrm{M}\right), \mathrm{LTC}_{4}\left(10^{-12}-10^{-8} \mathrm{M}\right)$, and ET-1 $\left(10^{-12}-10^{-8} \mathrm{M}\right)$ were examined in random order. Iloprost was a gift from Schering AG Pharmaceutical Research, Berlin. PGE 2 , histamine, SNP, $\mathrm{LTC}_{4}$, and ET-1 were purchased from Sigma Chemical Co., St. Louis, MO. Two or three agents were used per piglet. A cumulative dose-response study was performed for each drug by consecutively infusing the drug under the window in doses from lowest to highest. After infusion of these agents at each concentration, pial arteriolar diameter change was recorded every $2 \mathrm{~min}$ for $10 \mathrm{~min}$. After the use of an agent, at least $1 \mathrm{~h}$ elapsed before another agent was infused, and the cortical surface under the window was repeatedly flushed slowly with fresh aCSF that was kept bubbling with a mixture of $6.3 \% \mathrm{O}_{2} / 5.8 \% \mathrm{CO}_{2}$ in $\mathrm{N}_{2}$ to maintain $6.1 \mathrm{kPa} \mathrm{PcO}_{2}$ and $5.7 \mathrm{kPa} \mathrm{Po}_{2}$ at $37-38^{\circ} \mathrm{C}$ in a water bath. Before the use of a new drug, a control measurement was always taken.

All values are presented as means \pm SEM. A maximum of three arterioles were selected to study the percentage changes in pial arteriolar diameter in each animal. The means of the measurements from these arterioles were used as data points for the statistical analysis of the results. The results of the effects of stimuli on pial arteriolar diameter were subjected to two-way analysis of variance for repeated measures with Student-Newman-Keuls test to isolate differences between groups. A level of $p<0.05$ was considered significant. 


\section{RESULTS}

In the cerebral hematoma group, clotted blood remained around the cerebral vessels on the brain surface 4 $\mathrm{d}$ after blood injection. The blood clot and remnants covered a large area of the parietal cortex. Large clots over the surface were carefully removed if necessary. Clot remnants were evident around the vessels and did not obstruct view. No blood clots were present on the cerebral surface of the control group as a result of aCSF injection. Arterial $\mathrm{pH}, \mathrm{PaCO}_{2}, \mathrm{PaO}_{2}$, and mean arterial blood pressure were not different between the groups (Table 1). Diameters of the pial arterioles selected for measurement of responses were $126 \pm 8 \mu \mathrm{m}(n=25)$ and $115 \pm 9 \mu \mathrm{m}(n=24)$ for the control and hematoma groups, respectively.

Effects of cerebral hematoma on cerebral vasodilation. Topical application of iloprost in control animals dose dependently dilated pial arterioles to $54 \pm 3 \%$ at $10^{-8} \mathrm{M}$, the highest dose used (Fig. 1). This dilation was attenuated in the hematoma group to $23 \pm 3 \%$ at the same concentration.

Topical application of $\mathrm{PGE}_{2}$ dose dependently dilated pial arterioles in the control group to a percentage increase in diameter of $44 \pm 2$ at $10^{-5} \mathrm{M}$ (Fig. 2). Similarly to iloprost, dilation was attenuated in the hematoma group to $18 \pm 2 \%$ at the same concentration.

Histamine, applied topically, dose dependently dilated pial arterioles to a percentage increase in diameter of 67 \pm 4 at $10^{-5} \mathrm{M}$ concentration (Fig. 3 ) in the control group. Similarly to results from the prostanoids, the dilation induced by histamine was attenuated in the hematoma group $\left(34 \pm 3 \%\right.$ at $\left.10^{-5} \mathrm{M}\right)$.

Application of SNP dose dependently dilated pial arterioles in the control group to $50 \pm 7 \%$ of the original diameter. This dilation was not significantly affected in the hematoma group $\left(64 \pm 7 \%\right.$ at $10^{-5} \mathrm{M}$ ) (Fig. 4).

Effects of cerebral hematoma on cerebral vasoconstriction. Topical application of $\mathrm{LTC}_{4}$ constricted pial arterioles dose dependently [percentage decrease in diameter of $16 \pm 2$ at $10^{-8} \mathrm{M}$ in the control group (Fig. 5)]. The constrictions were potentiated in the hematoma group (36 $\pm 2 \%$ at $10^{-8} \mathrm{M}$ ).

Topical application of the lowest dose of ET-1 $\left(10^{-12}\right.$ M) caused significant dilation of pial arterioles up to $8 \%$ of the original diameter in the control group (Fig. 6). Higher doses dose dependently constricted the pial arterioles to a decrease in diameter of $26 \pm 3 \%$ at $10^{-8} \mathrm{M}$. The dilation induced by the lowest dose of ET-1 was absent after blood treatment, and the constrictions in-

Table 1. Blood gases, $p H$, and mean arterial blood pressure (MAP) of piglets

\begin{tabular}{lccccc}
\hline Groups & $n$ & $\mathrm{pH}$ & $\begin{array}{c}\mathrm{PaCO}_{2} \\
(\mathrm{kPa})\end{array}$ & $\begin{array}{c}\mathrm{PaO}_{2} \\
(\mathrm{kPa})\end{array}$ & $\begin{array}{c}\mathrm{MAP} \\
(\mathrm{kPa})\end{array}$ \\
\hline aCSF & 24 & $7.50 \pm 0.04$ & $4.4 \pm 0.3$ & $13.2 \pm 0.6$ & $9.5 \pm 0.5$ \\
Hematoma & 25 & $7.50 \pm 0.03$ & $3.9 \pm 0.1$ & $14.2 \pm 0.4$ & $9.4 \pm 0.3$ \\
\hline
\end{tabular}

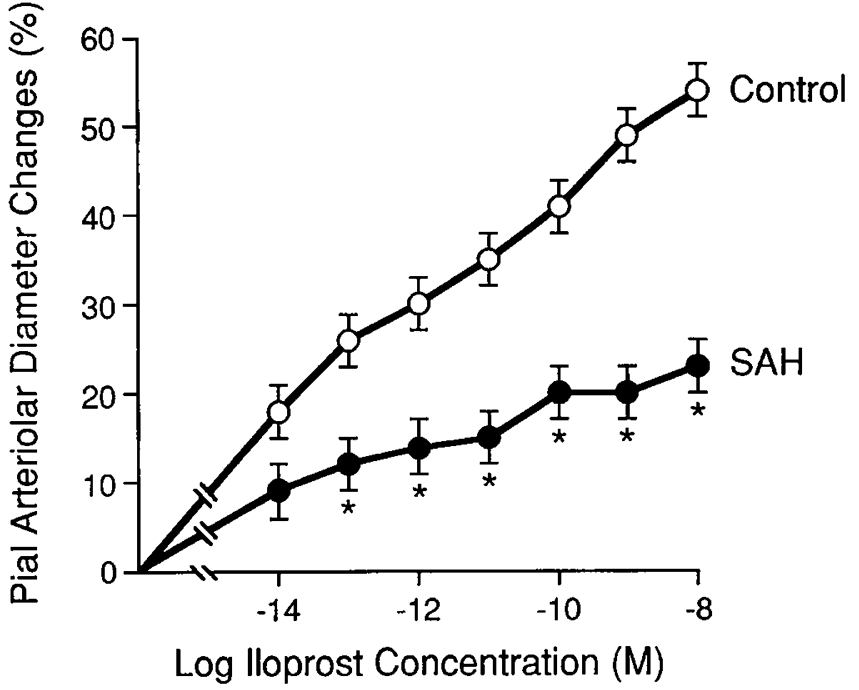

Figure 1. Pial arteriolar dilation in response to topical application of iloprost in the aCSF control group $(n=8)$ and in the subarachnoid hematoma $(S A H)$ group $(n=8) .{ }^{*}, p<0.05$ compared with the control.

duced by the higher concentrations were potentiated ( 43 $\pm 2 \%$ at $\left.10^{-8} \mathrm{M}\right)$.

\section{DISCUSSION}

The present results show that cerebral hematoma attenuates dilation of pial arterioles in response to $\mathrm{PGE}_{2}$, iloprost, and histamine but not in response to the nitrovasodilator SNP. In addition, vasoconstrictions in response to $\mathrm{LTC}_{4}$ and ET-1 were potentiated by hematoma.

The attenuation of cerebral vasodilation observed in this experiment is consistent with our previous findings that the cerebral presence of perivascular blood attenuates dilator responses to hypercapnia and hemorrhagic hypotension in newborn pigs (12). The results in newborn pigs have similarities to the findings from in vitro studies of brain arteries from rabbits with experimental he-

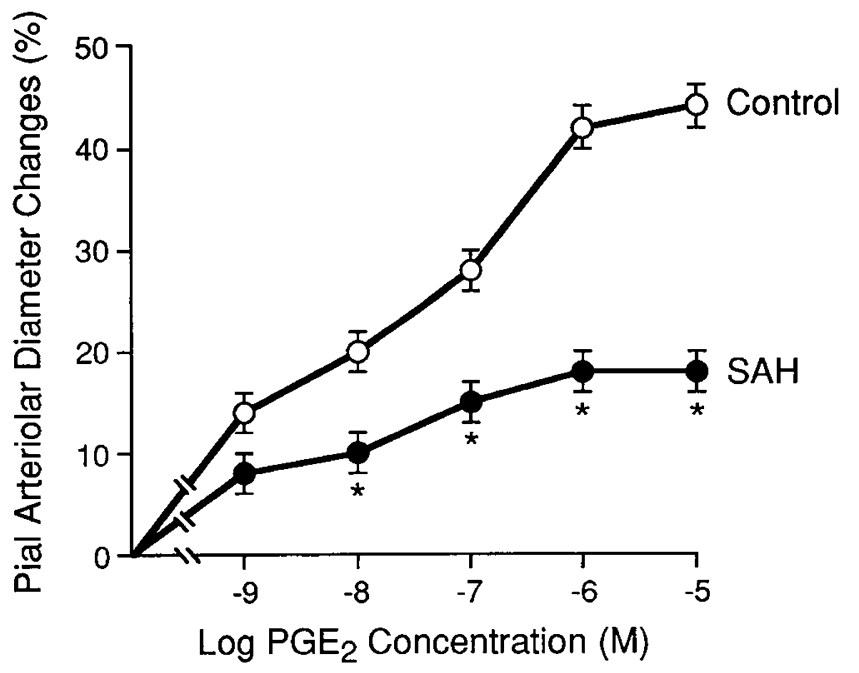

Figure 2. Pial arteriolar dilation in response to topical application of $\mathrm{PGE}_{2}$ in the aCSF control group $(n=9)$ and the subarachnoid hematoma $(S A H)$ group $(n=10) .{ }^{*}, p<0.05$ compared with the control. 


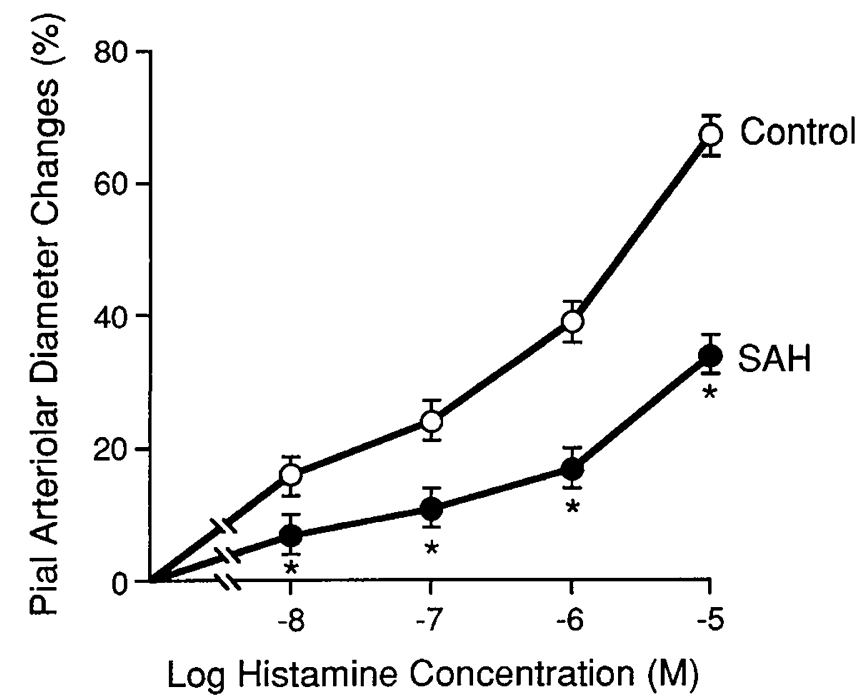

Figure 3. Pial arteriolar dilation in response to topical application of histamine in the aCSF control group $(n=12)$ and the subarachnoid hematoma $(S A H)$ group $(n=11) .{ }^{*}, p<0.05$ compared with the control.

matoma in which cerebral blood injection impaired endothelium-dependent dilation in response to adenosine triphosphate and acetylcholine (26). Similarly, dilation of basilar arteries in response to thrombin was reduced after subarachnoid hemorrhage, and that in response to vasopressin was abolished (27). Reduced dilation of arteries to stimulation by thrombin, bradykinin, and $\mathrm{Ca}^{2+}$ ionophore A23187 has been reported, whereas relaxation to SNP was not affected in basilar artery from human patients after subarachnoid hemorrhage (28).

The mechanism(s) by which cerebral vessels lose the ability to dilate in response to selective vasoactive stimuli after exposure to blood is not well understood. Among the conceivable mechanisms are reduced synthesis of dilatory prostanoids, impaired dilatory ability of the vascular smooth muscle, loss or reduced affinity of receptors

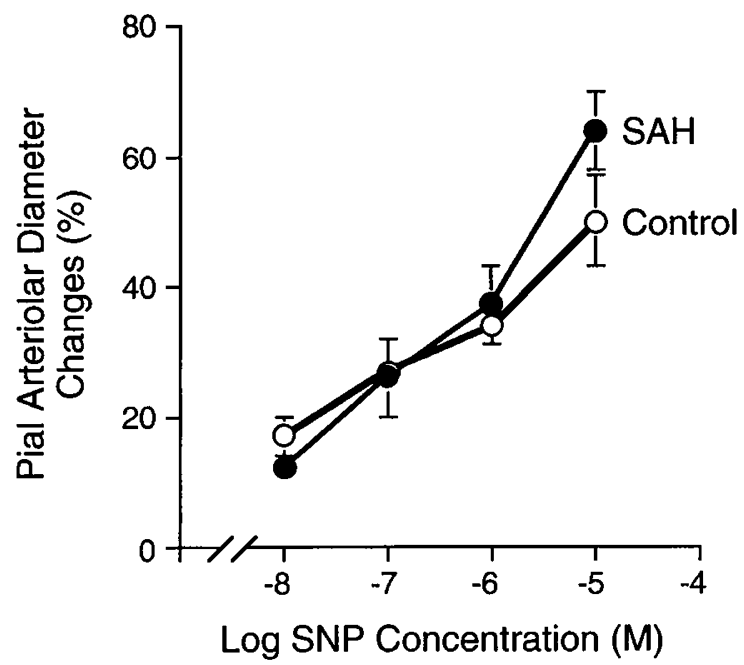

Figure 4. Pial arteriolar dilation in response to topical application of SNP in the aCSF control group $(n=5)$ and the subarachnoid hematoma $(S A H)$ group $(n=6)$.

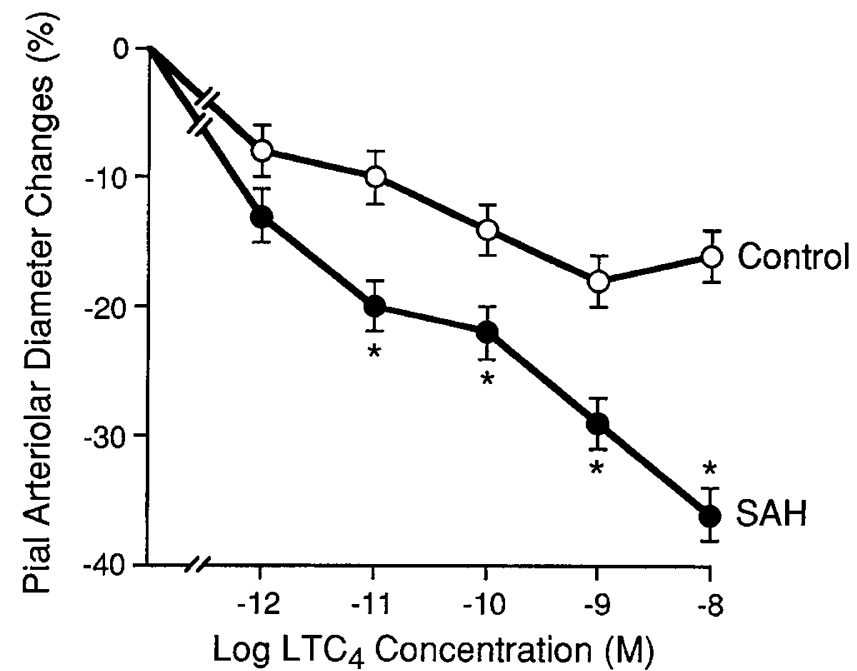

Figure 5. Pial arteriolar constriction in response to topical application of $\mathrm{LTC}_{4}$ in the aCSF control group $(n=9)$ and the subarachnoid hematoma ( $S A H$ ) group $(n=9) .{ }^{*}, p<0.05$ compared with the control.

to specific dilator agents, or alteration of second messenger pathways. Reductions in the synthesis of dilator prostanoids have been reported in animal models of subarachnoid hemorrhage $(15,17,22,24)$. Precipitating events may involve activated oxygen species. Extravascular cerebral blood can generate substantial amounts of superoxide anion in both in vitro and in vivo preparations using newborn pigs (29). Initially, a major source of superoxide anion appears to be cyclooxygenase of platelets (29). Thereafter, free radicals may be produced via the release of the components of hemolyzed erythrocytes such as $\mathrm{Hb}$ and other blood proteins (30-32). Oxyhemoglobin, one of the components of blood clots, spontaneously autoxidizes to methemoglobin, potentially releasing superoxide anion radical (32). The generation of oxygen free radicals may have deleterious effects on the endothelial and smooth muscle cells, resulting in altered receptor char-

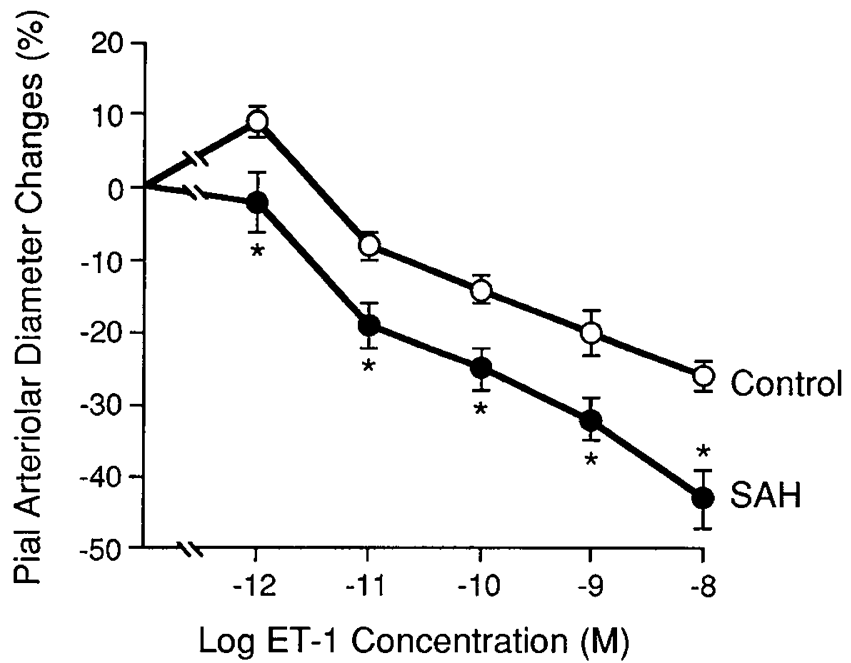

Figure 6. Pial arteriolar responses to topical application of ET-1 in the aCSF control group $(n=7)$ and the subarachnoid hematoma $(S A H)$ group $(n=8) .{ }^{*}, p<0.05$ compared with the control. 
acteristics to prostanoids once they are formed as well as downstream mechanisms involved in vascular smooth muscle dilation.

In this study, selective attenuation of vasodilations produced by $\mathrm{PGE}_{2}$, iloprost, and histamine were observed, whereas vasodilation produced by SNP was not affected. Prostanoids are involved in histaminergic cerebral vasodilation in piglets (33). Prostanoids cause vasodilation via the activation of adenylyl cyclase (34). In contrast, nitrovasodilators act by stimulation of soluble guanylyl cyclase (35). It is therefore possible that the mechanism by which hematoma attenuates vasodilation by these agents involves interference with the ability of these agents to stimulate generation of cAMP. However, the inhibition appears specific for pathways involving prostanoids because dilation in response to isoproterenol, which also is via cAMP, is not inhibited (12). Thus, the possibility of inhibition of a specific adenylyl cyclase coupled to prostanoid (probably prostacyclin) receptors or inhibition of receptor binding or coupling within the pathway must be suggested.

In the present study, we also observed that the responses of cerebral arterioles to topical application of the vasoconstrictor agents $\mathrm{LTC}_{4}$ and ET-1 were significantly potentiated by the presence of cerebral hematoma. Specifically, pial arteriolar dilation in response to ET- 1 at the lowest concentration $\left(10^{-12} \mathrm{M}\right)$ in the control animals, which was consistent with our earlier observation (11), did not occur in piglets with cerebral hematoma. The other concentrations used constricted the pial arterioles, and the constrictions were potentiated by hematoma. ET-1-induced vasoconstrictions lasted for a long time and took persistent washing to return to the preconstriction diameter. Such prolonged vasoconstriction is consistent with earlier observations (11). Also consistent with our observation was the reported enhanced vasoconstriction to ET-1 in cerebral arteries from rats with subarachnoid hemorrhage (36). Increased synthesis of vasoconstrictors $\mathrm{LTC}_{4}$, ET-1, thromboxane $\mathrm{B}_{2}$, and $\mathrm{PGF}_{2 \alpha}$ has been reported in newborn and adult animal models, as well as in human patients with subarachnoid hemorrhage $(6,8,14,23,37)$. Furthermore, in adult animal models of subarachnoid hemorrhage and in clinical cases, reduced dilator prostanoid synthesis and increased constrictor prostanoid synthesis have been observed $(4,6,8)$. Decreased vasodilator influence from prostanoids and unopposed activation of some vasoconstrictor stimulus, combined with possible endothelial damage with adherence of platelets and leukocytes and release of vasoconstricting agents, could contribute to the enhanced vasoconstriction observed. Dilator prostanoids serve as inhibitors to constrictions induced by some vasoconstrictor agents including ET- 1 and $\mathrm{LTC}_{4}$ so that, with reduced effectiveness of prostanoids, potentiated vasoconstriction might be produced. Also, different pathophysiologic conditions including subarachnoid hemorrhage have been reported to stimulate the release of endotheliumdependent contracting factors (38). These factors could contribute to the enhanced vasoconstriction to ET-1 and $\mathrm{LTC}_{4}$ observed in this study.

Alternatively, because increased synthesis of various vasoactive agents has been reported after hemorrhage (4, $6,8,14,18,37)$, interactions between two released substances might play a role in the observed vasoconstriction. Increased levels of serotonin have been reported to suppress the ability of the perivascular trigeminal system to release vasodilator neuropeptides (39). ET-1 has been reported to potentiate serotonin-induced contraction of porcine coronary artery rings (40), whereas pretreatment of rat aortic rings with threshold concentrations of serotonin potentiated the subsequent contractile response to ET-1 (41).

The present study reveals that cerebral hematoma reduces the vasodilation and potentiates the vasoconstriction induced by specific dilator and constrictor agents, respectively. The mechanism by which perivascular blood produces these changes is not clear. However, the selective attenuation of prostanoid-dependent vasodilation indicates that the mechanism may involve an effect on the prostanoid/cAMP signaling pathway. In addition, increased synthesis of vasoconstrictor agents as a result of perivascular blood coupled with loss of prostanoid dilator influences may lead to the potentiation of the vasoconstrictor action observed in the reported experiments and to the generalized vasoconstriction reported previously in piglets with cerebral hematoma (18).

Acknowledgments. The authors thank Mildred Jackson, Stanley Lopez, Alex Fedinec, and Demecca Puryear for their technical assistance; Danny Morse and Laura Malinick for the illustrations; and Maria Swayze for secretarial assistance.

\section{REFERENCES}

1. Jocelyn LJ, Casiro OG 1992 Neurodevelopmental outcome of term infants with intraventricular hemorrhage. Am J Dis Child 146:194-197

2. Bada HS, Green RS, Pourcyrous M, Leffler CW 1989 Indomethacin reduces the risks of severe intraventricular hemorrhage. J Pediatr 115:631-637

3. White RP, Leffler CW, Bada HS 1990 Eicosanoid levels in CSF of premature infants with posthemorrhagic hydrocephalus. Am J Med Sci 299:230-235

4. Kassell NF, Sasaki T, Colohan ART, Nazar G 1985 Cerebral vasospasm following aneurysmal subarachnoid hemorrhage. Stroke 16:562-572

5. Seiler HJ, Reulen HJ, Huber P, Grolimund P, Ebeling U, Steiger HJ 1988 Outcome of aneurysmal subarachnoid hemorrhage in a hospital population: a prospective study including early operation, intravenous nimodipine, and transcranial Doppler ultrasound. Neurosurgery 23:598-604

6. Macdonald RL, Wier BKA 1991 A review of hemoglobin pathogenesis of cerebral vasospasm. Stroke 22:971-982

7. Miyaoka M, Nonaka T, Watanabe H, Chigasaki H, Ishii S 1976 Etiology and treatment of prolonged vasospasm: experimental and clinical studies. Neurol Med Chir (Tokyo) 16:103-114

8. Findlay JM, Macdonald LR, Weir KA 1991 Current concepts of pathophysiology and management of cerebral vasospasm following aneurysmal subarachnoid hemorrhage. Cerebrovasc Brain Metab 3:336-361

9. Leffler CW, Armstead WM, Shibata M 1993 Role of the eicosanoids in cerebral hemodynamics. In: Phillis JW (ed) The Regulation of Cerebral Blood Flow. CRC Press, Ann Arbor, MI, pp 297-313

10. Yanagisawa M, Masaki T 1989 Endothelin, a novel endothelium-derived peptide. Pharmacological activities, regulation and possible roles in cardiovascular control. Biochem Pharmacol 38:1877-1883

11. Armstead WM, Mirro R, Leffler CW, Busija DW 1989 Influence of endothelin on piglet cerebral microcirculation. Am J Physiol 26:H707-H710

12. Busija DW, Leffler CW 1991 Selective attenuation by perivascular blood of prostanoid-dependent cerebrovascular dilation in piglets. Stroke 22:484-488

13. Busija DW, Leffer CW 1990 Perivascular blood attenuates noradrenergic but not cholinergic effects on piglet pial arterioles. Stroke 21:441-446 
14. Walker V, Pickard JD 1985 Prostaglandins, thromboxane, leukotrienes and cerebral circulation in health and disease. Adv Tech Stand Neurosurg 12:3-90

15. Sasaki T, Murota S, Wakai S, Asano T, Sano K 1981 Evaluation of prostaglandin biosynthetic activity in canine basilar artery following subarachnoid injection of blood. J Neurosurg 55:771-778

16. Maeda Y, Tani E, Miyamoto T 1981 Prostaglandin metabolism in experimental cerebral vasospasm. J Neurosurg 55:779-785

17. Nosko M, Schulz R, Wier B, Cook DA, Grace M 1988 Effects of vasospasm on levels of prostacyclin and thromboxane $A_{2}$ in cerebral arteries of the monkey. J Neurosurg 22:44-50

18. Parfenova H, Shibata M, Leffler CW 1993 Subarachnoid blood causes pial arteriolar constriction in newborn pigs. Stroke 24:1729-1734

19. Kiwak KJ, Moskowitz MA, Levini L 1985 Leukotrienes production in gerbil brain after ischemic insults, subarachnoid hemorrhage and concussive injury. J Neurosurg 62:865

20. Paoletti $P$, Gaetani $P$, Grignani $B$, Pacchiarini L, Silvani V, Rodriguez $Y$, Baena R 1988 CSF leukotrienes $C_{4}$ following subarachnoid hemorrhage. J Neurosurg 69:488-493

21. Rodriguez Y, Baena R, Gaetani P, Grignani G, Pacchiarini L 1987 Effects of nimodipine on arachidonic acid metabolites after subarachnoid hemorrhage. Acta Neurol Scand 76:267-271

22. Rodriguez Y, Baena R, Gaetani P, Paoletti P 1988 A study on cisternal CSF levels of arachidonic acid metabolites after aneurysmal subarachnoid hemorrhage. J Neurosurg 84:329-335

23. Kraus GE, Bucholz RD, Yoon KW, Knuepfer MM, Smith Jr KR 1991 Cerebrospinal fluid endothelin-1 and endothelin-3 levels in normal and neurosurgical patients: a clinical study and literature review. Surg Neurol 35:20-29

24. Seifert V, Stolke D, Kaever V, Dietz H 1987 Arachidonic acid metabolism following aneurysm rupture: evaluation of cerebrospinal fluid and serum concentrations of 6-keto-prostaglandin $F_{1 \alpha}$ and thromboxane $B_{2}$ in patient with subarachnoid hemorrhage. Surg Neurol 27:234-252

25. Masaoka H, Suzuki R, Hirata Y, Emori T, Marumo F, Hirakawa K 1990 Raised plasma and cerebrospinal fluid endothelin in aneurysmal subarachnoid hemorrhage. In: Sano K, Takakura K, Kassell NF, Sasaki T (eds) Cerebral Vasospasm. University of Tokyo Press, Tokyo, pp 266-268

26. Nakagomi T, Kassell NF, Sasaki T, Fujiwara S, Lehman RM, Torman JC 1987 Impairment of endothelium-dependent vasodilation induced by acetylcholine and adenosine triphosphate following experimental subarachnoid hemorrhage. Stroke 18:482-489

27. Kim P, Sundt TM, Vanhoutte PM 1988 Alterations in endothelium-dependent responsiveness of the canine basilar artery after subarachnoid hemorrhage and vasospasm in dogs. J Neurosurg 69:239-246

28. Hatake K, Wakabayashi I, Kakishita E, Hishida S 1992 Impairment of endothelium-dependent relaxation in human basilar artery after subarachnoid hemorrhage. Stroke 23:1111-1117

29. Mirro R, Armstead WM, Busija DW, Leffler CW 1989 Blood-induced superoxide anion generation by newborn pig cerebral cortex. Am J Physiol 257:H1560-H1564

30. Sadradez SMWH, Anderson DK, Panter SS, Hallaway PE, Eaton JW 1987 Hemoglobin potentiates central nervous system damage. J Clin Invest 79:662664

31. Mullane KM 1989 Neutrophil-platelet interactions and post-ischemia myocardial injury. In: Schnov K, Singinger H (eds) Prostaglandin Clinical Research: Cardiovascular System. Alan R. Liss, New York, pp 39-51

32. Wever R, Oudega B, van Gelder BF 1973 Generation of superoxide radicals during the autoxidation mammalian oxyhemoglobin. Biochim Biophys Acta 302:475-478

33. Mirro R, Busija DW, Armstead WM, Leffler CW 1988 Histamine dilates pia arterioles of newborn pigs through prostanoid production. Am J Physiol 254:H1023-H1026

34. Parfenova $\mathrm{H}$, Shibata $\mathrm{M}$, Samuel $\mathrm{Z}$, Leffler $\mathrm{CW} 1994 \mathrm{CO}_{2}$ and cerebral circulation in newborn pigs: cyclic nucleotides and prostanoids in vascular regulation. Am J Physiol 266:H1494-H1501

35. Kukovetz WR, Holzmann S, Schmidt K 1991 Cellular mechanisms of action of therapeutic nitric oxide donors. Eur Heart J 12(suppl E):16-24

36. Alafaci C, Jansen I, Arbab MA-R, Shiokawa Y, Svendgaard N-AA, Edvinsson $L 1990$ Enhanced vasoconstrictor effect of endothelin in cerebral arteries from rats with subarachnoid haemorrhage. Acta Physiol Scand 138:317-319

37. Fujimori A, Yanagisawa M, Saito A, Goto K, Masaki T, Takakura K, Shigeno $T 1990$ Endothelin in plasma and cerebrospinal fluid of patients with subarachnoid hemorrhage. Lancet 336:633

38. Luscher TH, Boulanger CM, Dohi Y, Yang Z 1992 Endothelium derived contracting factors. Hypertension 19:117-130

39. Moskowitz MA, Macfarlane R 1993 Neurovascular and molecular mechanisms in migraine headaches. Cerebrovasc Brain Metab Rev 5:159-177

40. Yang BC, Nichols WW, Lawson DL, Mehta JL 1992 5-Hydroxytryptamine potentiates vasoconstrictor effect of endothelin-1. Am J Physiol 262:H931H936

41. Nakayama K, Ishigai Y, Uchida H, Tanaka Y 1991 Synergistic coronary vasoconstriction produced by endothelin-1 in combination with hydroxytryptamine. J Cardiovasc Pharmacol 17:S179-S181 